\title{
Response in peripheral plasma melatonin to photoperiod change and the effects of exogenous melatonin on seasonal quiescence in the tammar, Macropus eugenii
}

\author{
S. J. McConnell* and C. H. Tyndale-Biscoe $\dagger$ \\ Department of Behavioural Biology, Research School of Biological Sciences, Australian National \\ University, G.P.O. Box 4, Canberra, A.C.T. 2601, and †Division of Wildlife and Rangelands \\ Research, CSIRO, P.O. Box 84, Lyneham, A.C.T. 2602, Australia
}

\begin{abstract}
Summary. During the light phase of each of 3 photoperiods tested, plasma melatonin concentrations were $<16$ to $62 \mathrm{pg} / \mathrm{ml}$ and during the dark phase they were 31 to 169 $\mathrm{pg} / \mathrm{ml}$. When the photoperiod to which the tammars were exposed was altered from $15 \mathrm{~h}$ light: $9 \mathrm{~h}$ dark to $12 \mathrm{~L}: 12 \mathrm{D}$ the onset of the nocturnal rise in melatonin was advanced from the first day, thereby extending its duration, and the females gave birth $32 \pm 0.4$ (mean \pm s.e.m.) days later. To test whether melatonin mediated this effect of photoperiod change, tammars in a second group were injected s.c. with melatonin $(400 \mathrm{ng} / \mathrm{kg}$, $\mathrm{N}=6)$ or the arachis oil vehicle $(\mathrm{N}=6), 2 \cdot 5$ to $2 \cdot 25 \mathrm{~h}$ before dark during $15 \mathrm{~L}: 9 \mathrm{D}$ for 15 days before exposure to $12 \cdot 5 \mathrm{~L}: 11 \cdot 5 \mathrm{D}$. The melatonin injections mimicked the endogenous melatonin profile of $12 \mathrm{~L}: 12 \mathrm{D}$ and the melatonin-injected tammars gave birth $32 \pm 0.8$ days after the start of injections, which was the same as the interval from photoperiod change in Exp. 1 but was significantly different $(P<0.005)$ from the interval in the control group ( $46.0 \pm 1 \cdot 1$ days). These results show that exogenous melatonin given 2.5 to $2.25 \mathrm{~h}$ in advance of the endogenous rise fully mimics the response of the tammar to photoperiod change.
\end{abstract}

\section{Introduction}

In a variety of eutherian mammals the pineal gland has been shown to be involved in the response to annual changes in photoperiod that control seasonal reproduction (Reiter, 1974; Lincoln, Almeida, Klandorf \& Cunningham, 1982). A characteristic feature of pineal physiology is a circadian pattern in the secretion of melatonin, with highest levels during the dark phase, and it appears to be a component of this pattern that provides the photoperiodic time measurement for reproductive responses (Lincoln, 1983). In sheep the duration of the nocturnal rise of circulating melatonin corresponds closely to the duration of the dark phase (Kennaway, Sanford, Godfrey \& Friesen, 1983) and oral administration of melatonin to ewes under long daylength, which mimics the duration of the nocturnal profile of short daylength, can induce cyclic ovarian activity within 65 days (Kennaway, Gilmore \& Seamark, 1982). In pinealectomized Djungarian hamsters, daily melatonin infusions of $12 \mathrm{~h}$ duration induced testicular regression within 12 days (Carter \& Goldman, 1983); however, as serial blood samples were not taken the melatonin profiles resulting from the infusions are not known.

Manipulation of photoperiod has been shown to influence reproduction in at least three species of marsupial (see Tyndale-Biscoe, 1980) and the pineal has been implicated in one of these, the

\footnotetext{
* Present address: Institut für Tierzucht und Tierverhalten, Mariensee 3057, Neustadt 1, Federal Republic of Germany. 
tammar (Macropus eugenii) (Renfree, Lincoln, Almeida \& Short, 1981). The tammar may prove to be a particularly suitable species in which to examine pineal function in reproduction as it responds within 6 days to photoperiod change (Sadleir \& Tyndale-Biscoe, 1977; Hinds \& den Ottolander, $1983)$ and because of its size (4-5 kg) frequent serial blood samples can be taken without undue effect on the animal.

The tammar is a strict seasonal breeder in which $80 \%$ of the females give birth in late January or early February in southern Australia (Andrewartha \& Barker, 1969). Birth is followed within 1 day by post-partum oestrus and ovulation and the resultant corpus luteum $(C L)$ remains quiescent during lactation. If conception occurs the embryo develops to a unilaminar blastocyst and remains in diapause while the $\mathrm{CL}$ is quiescent (Renfree, 1981). Before the winter solstice in June, while the females experience decreasing daylength, both the CL and the blastocyst will resume development if lactation is terminated by removing the pouch young and birth will occur 26-27 days later (Merchant, 1979). However, after the winter solstice removal of the pouch young does not initiate development and the embryo remains in diapause throughout the period of increasing daylength (Renfree, 1981). This is termed seasonal quiescence and it terminates naturally after the summer solstice. Exposure to photoperiod equivalent to summer daylength ( $15 \mathrm{~h}$ light: $9 \mathrm{~h}$ dark) per se did not induce reactivation but a decrease from 15L :9D to $12 \mathrm{~L}: 12 \mathrm{D}$ did and births occurred $33.7 \pm 2.5$ days later (mean \pm s.d.) (Sadleir \& Tyndale-Biscoe, 1977). This is 6-7 days longer than the interval after removing the pouch young during decreasing daylength and has been shown to be due to a delay in the response of the CL (Hinds \& den Ottolander, 1983). Denervation of the pineal gland before the winter solstice abolished the nocturnal elevation of plasma melatonin and the subsequent seasonal diapause (Renfree et al., 1981). When the pouch young of these animals were removed during the period of increasing daylength births occurred 27-28 days later, as would occur in intact females experiencing natural decreasing daylength. These results implicate the pineal in the sensitivity of tammars to photoperiod change, which may be effected by changes in plasma melatonin concentrations.

The aims of the present study were to determine whether exposure of tammars to a photoregimen known to induce reactivation of the $\mathrm{CL}$ and blastocyst would alter the circadian melatonin profile and, if so, whether exogenous melatonin treatment that mimicked these endogenous changes would also induce reactivation.

\section{Materials and Methods}

\section{Animals}

Adult female tammars without pouch young were taken from the breeding colony at the Division of Wildlife and Rangelands Research, Canberra, in July, when they could be expected to be in seasonal quiescence, and were maintained on a diet of pelletted lucerne chaff and oats and water ad libitum.

Experiment 1. Four females were housed in separate cages $(90 \times 73 \times 111.5 \mathrm{~cm})$ in a controlled temperature $\left(24^{\circ} \mathrm{C}\right)$ and photoperiod room. Illumination was provided by four Osram 'Daylight' fluorescent tubes, which provided up to $4325 \mathrm{~cd} \mathrm{~m}^{-2}$ in the cages. A $15-\mathrm{W}$ red pilot lamp provided low illumination during the dark periods. The tammars were exposed to a photoregimen of $10 \mathrm{~h}$ light: $14 \mathrm{~h}$ dark (10L :14D) for 14 days, $15 \mathrm{~L}: 9 \mathrm{D}$ for 40 days, then $12 \mathrm{~L}: 12 \mathrm{D}$ for 15 days (Text-fig. 1a). Lights went on at 07:00 h each day. The first day of 12L:12D was designated Day 0. Blood samples were taken at intervals of $2-4 \mathrm{~h}$ on one day of each of the first two photoperiods and on Days 0 and 5. Additional samples were also taken on Days 0-5 at 18:00, 19:00, 20:00, 21:00 and 22:00 $\mathrm{h}$ to cover the extended dark phase. On Day 15, when the blastocysts could be expected to have been reactivated, the tammars were transferred to an outside pen at ambient photoperiod of $12 \cdot 5 \mathrm{~L}: 11 \cdot 5 \mathrm{D}$ and were run with sexually mature males to detect post-partum oestrus. Daily checks for birth and copulatory plugs, indicative of oestrus, began on Day 27. On Day 46 the new young 


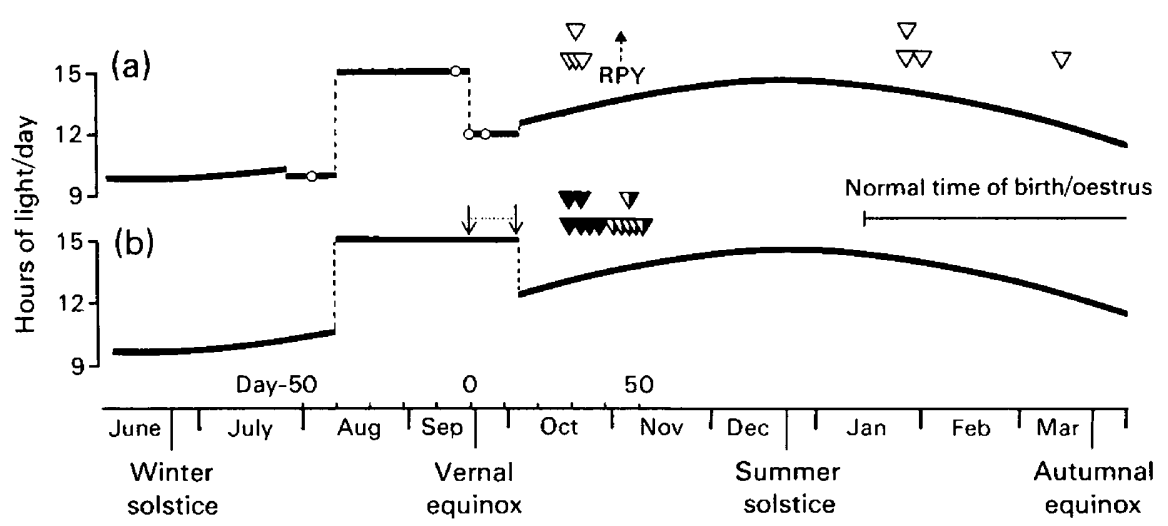

Text-fig. 1. The design and results of Exps 1 and 2. In Exp. 1(a) the tammars were exposed to $10 \mathrm{~L}: 14 \mathrm{D}$, then $15 \mathrm{~L}: 9 \mathrm{D}$ and finally, to induce reactivation, $12 \mathrm{~L}: 12 \mathrm{D}$. Births occurred $(\nabla) 31-$ 33 days later. After removal of these pouch young (RPY) births occurred at the normal time after the summer solstice (see (b)). Blood samples were taken each $1-4 \mathrm{~h}$ on the days indicated by $O$ to determine the circadian profile of melatonin. In Exp. 2(b) 12 tammars were subjected to a similar photoregimen except that they were maintained in $15 \mathrm{~L}: 9 \mathrm{D}$ for an additional 15 days during which time they received a daily injection of melatonin or placebo (l) $2 \cdot 5-2 \cdot 25 \mathrm{~h}$ before lights off. Births and post-partum oestrus of melatonin-treated tammars $(\nabla)$ and placebo-treated controls $(\nabla)$ are indicated.

were removed from the pouches and the females were checked twice-weekly from Day 76 for further new pouch young.

Experiment 2. A group of 12 females was exposed to a photoregimen similar to that in Exp. 1 except that the photoperiod from Days 0 to 14 was maintained at $15 \mathrm{~L}: 9 \mathrm{D}$ and then the animals were returned to outside pens with males at ambient photoperiod of $12.5 \mathrm{~L}: 11 \cdot 5 \mathrm{D}$, an extension of the dark phase of $2.5 \mathrm{~h}$ (Text-fig. 1b). On Day 0 the tammars were randomly assigned to two groups and from Days 0 to 14, 6 received a daily subcutaneous injection of melatonin (Sigma Chemical Co., St Louis, MO, U.S.A.) in arachis oil ( $400 \mathrm{ng} / \mathrm{kg}$ body weight) and 6 received a daily injection of arachis oil alone. The tammars were injected each day between $19: 30$ and $19: 45 \mathrm{~h}$, which was $2 \cdot 5-$ $2.25 \mathrm{~h}$ before lights off. From Day 27, 2 days before the first births could be expected, all the animals were checked daily until birth and/or oestrus was detected.

Blood sampling. At the start of each period of blood sampling a 20-gauge indwelling catheter (Surflo: Termo Corpn, Tokyo, Japan) was placed in a lateral tail vein and sequential samples of 5 $\mathrm{ml}$ blood were withdrawn into sterile heparinized syringes. After separation of the plasma the blood cells were suspended in sterile buffered sodium citrate and returned after the subsequent bleed to maintain normal haematocrit. The catheter was flushed with $0.2 \mathrm{ml}$ heparinized saline (250 i.u./ml). Plasma samples were stored at $-15^{\circ} \mathrm{C}$ until assayed for melatonin.

\section{Melatonin assay}

Melatonin was measured by the radioimmunoassay of Kennaway et al. (1982), which was validated in this study for the tammar. The antiserum to melatonin (G280), kindly provided by $\mathrm{Dr}$ D. J. Kennaway, Department of Obstetrics and Gynaecology, University of Adelaide, was raised in a goat against a melatonin-bovine $\gamma$-globulin conjugate. Cross-reactivities at the $50 \%$ displacement level were reported by the supplier to be : 6-hydroxymelatonin $(0.02 \%), 6$-sulphatoxymelatonin $(0.3 \%), N$-acetyl-serotonin $(0.3 \%), N$-acetyl-tryptamine $(0.4 \%)$, 5-methoxytryptamine $(0.01 \%)$, 5-methoxytryptophol $(0.01 \%)$, serotonin $(0.10 \%)$ and $O$-acetyl-5-methoxy-tryptophol $(0 \cdot 06 \%)$ (Kennaway et al., 1982). 
Procedure. Potassium tetraborate buffer $(1 \mathrm{ml}, 0 \cdot 5 \mathrm{M}, \mathrm{pH} 9 \cdot 6)$ was added to $1 \mathrm{ml}$ plasma sample (in duplicate) and lipid was extracted with petroleum spirit (b.p. $60-80^{\circ} \mathrm{C}$ ). The melatonin was then extracted with $6 \mathrm{ml}$ dichloromethane-hexane $(1: 1 \mathrm{v} / \mathrm{v})$. A melatonin standard curve in the range of $0-1000 \mathrm{pg}$ (in BSA-BGG-PO ${ }_{4}$ buffer) was treated identically.

At a final dilution of 1:41 200 the antibody bound $40.6 \pm 3.5 \%$ (mean \pm s.d.) of the [ $\left.{ }^{3} \mathrm{H}\right]$ melatonin (sp. act. $31 \mathrm{Ci} / \mathrm{mmol}$ : New England Nuclear Corp., Boston, MA, U.S.A.). Sensitivity of the assay (lowest standard being displaced more than two standard deviations from the zero standard) was $20.5 \pm 9.0 \mathrm{pg} /$ tube $(n=16)$. Blank values (ligand-free plasma and solvent) were less than the assay sensitivity and were not corrected for. The intra-and interassay coefficients of variation were determined from a common plasma pool $(\sim 240 \mathrm{pg} / \mathrm{ml})$. The interassay coefficient of variation was $16.7 \%$, measured in duplicate samples in 15 assays, and the intra-assay coefficient of variation was $4 \cdot 5-10 \cdot 5 \%$ determined from 8 replicates in 4 assays.

Parallelism of dose-response curves. Two series of melatonin standards (15.6-1000 pg/tube) in triplicate were set up in assay buffer or in plasma from a pinealectomized tammar. A tammar pineal gland was homogenized in assay buffer and, after centrifugation, triplicate aliquants (10$500 \mu \mathrm{l})$ of the supernatant were taken. These and triplicate aliquants $(200-1000 \mu \mathrm{l})$ of charcoalstripped tammar plasma, and of plasma collected in the dark phase from an intact tammar, were all extracted and assayed as previously described. The displacement curves obtained from the normal plasma, plasma with standards, and pineal extract, were parallel to the buffer standard displacement curve, indicating that factors in tammar plasma and pineal tissue did not interfere in the assay, and that the endogenous hormone behaved similarly to the standard hormone (Text-fig. 2).

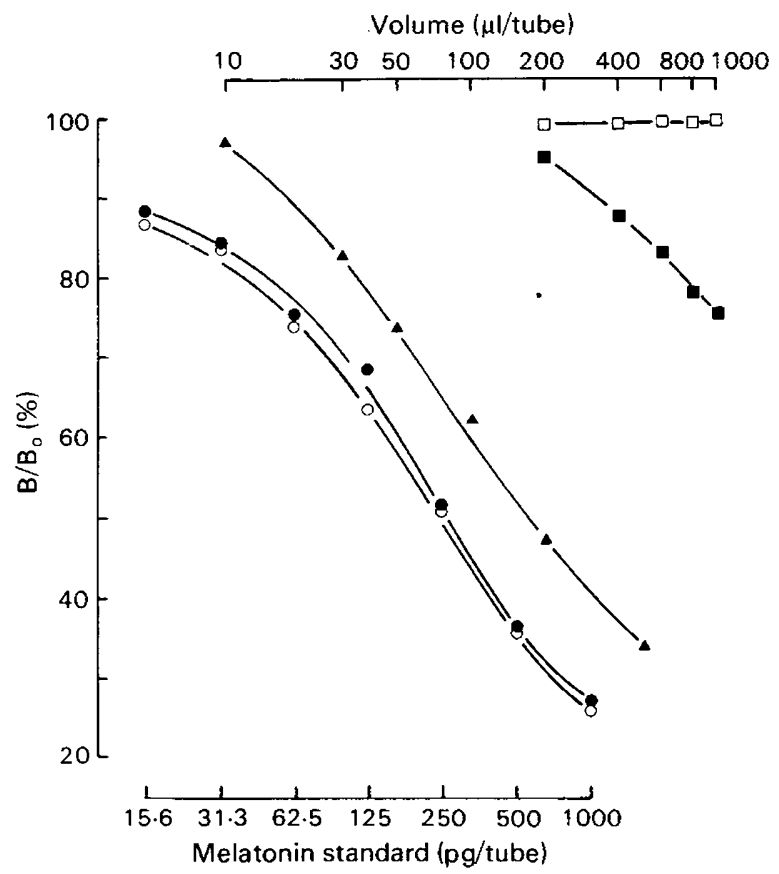

Text-fig. 2. Dose-response curves for melatonin standard added to assay buffer $(\mathcal{O})$, pinealectomized tammar plasma $(O)$ and for different dilutions of a tammar pineal homogenate $(\boldsymbol{A})$, plasma taken from an intact tammar in the dark phase ( $\boldsymbol{D})$, and charcoalstripped tammar plasma $(\square)$. B, amount of $\left[{ }^{3} \mathrm{H}\right]$ melatonin bound in the presence of unlabelled exogenous or endogenous hormone; $B_{0}$, amount of $\left[{ }^{3} \mathrm{H}\right]$ melatonin bound in the absence of unlabelled hormone. 
Recovery of exogenous melatonin. The efficiency of extraction of melatonin was determined by the addition of $\left[{ }^{3} \mathrm{H}\right]$ melatonin to $1 \mathrm{ml}$ aliquants of tammar plasma or buffer containing $0,31,125$ or $500 \mathrm{pg}$ unlabelled melatonin. Recovery was $81.42 \pm 3.16 \%$ (plasma, mean \pm s.e.m.) and $80.67 \pm$ $1.84 \%$ (buffer, mean \pm s.e.m.).

A further series of melatonin standards $(50-1000 \mathrm{pg})$ was added to $1 \mathrm{ml}$ aliquants of a charcoalstripped tammar plasma pool and extracted and assayed as described. The melatonin concentration of each sample was determined by reference to a similarly treated standard curve in buffer. The amount of melatonin added to charcoal-stripped tammar plasma was similar to that measured after assay, within this range. The regression equation for melatonin added $(x)$ plotted against melatonin measured $(y)$ was $y=0.975 x+4.923$, with a correlation coefficient $=0.999$. These results show that the assay measured the melatonin concentration in tammar plasma accurately and also indicated a lack of interference in the assay from non-hormonal constituents of tammar plasma.

To determine the recovery of exogenous melatonin in vivo, one female tammar in 15L : $9 \mathrm{D}$ was injected subcutaneously with a solution of melatonin in arachis oil at doses of $1 \mu \mathrm{g} / \mathrm{kg}$ body weight and $400 \mathrm{ng} / \mathrm{kg}$ body weight, given 1 week apart. Blood samples were taken at frequent intervals before and after injection, during the light phase. Subsequently, the same animal was sampled at intervals of $0.5-2 \mathrm{~h}$, from $2.6 \mathrm{~h}$ before lights off until $1 \mathrm{~h}$ after lights on, on 2 successive days. On the 2nd day the $400 \mathrm{ng} / \mathrm{kg}$ dose of melatonin was injected $2.5 \mathrm{~h}$ before lights off. Melatonin was assayed in all these samples.

\section{Results}

\section{Experiment 1}

All 4 tammars gave birth and came into oestrus $32 \pm 0.4$ days after the photoperiod change from 15L:9D to $12 \mathrm{~L}: 12 \mathrm{D}$ (Table 1; Text-fig. 1a). This interval is 6 days longer than that after removing the pouch young during decreasing daylength (26.2 \pm 0.67 days; Merchant, 1979). After removal of the pouch young on Day 46 (4 November), birth and/or oestrus were not detected until the start of the new breeding season in January-March (Text-fig. 1).

Table 1. Intervals to birth and oestrus in tammars subjected to decreased photoperiod (Exp. 1), or to pretreatment with single daily injections of melatonin or the vehicle $2 \cdot 5$ to $2 \cdot 25 \mathrm{~h}$ before lights off for 15 days before decreased photoperiod (Exp. 2)

\begin{tabular}{|c|c|c|c|c|c|}
\hline \multirow[b]{2}{*}{ Exp. } & \multirow{2}{*}{$\begin{array}{l}\text { Pretreatment } \\
\text { (Days 0-14) }\end{array}$} & \multicolumn{2}{|c|}{$\begin{array}{l}\text { Interval (days) from } \\
\text { photoperiod change to: }\end{array}$} & \multicolumn{2}{|c|}{$\begin{array}{l}\text { Interval (days) from } \\
\text { start of pretreatment to: }\end{array}$} \\
\hline & & Birth & Oestrus & Birth & Oestrus \\
\hline 1 & - & $\mathrm{a} 32 \cdot 0 \pm 0.4(4)$ & $\mathrm{b} 32.0 \pm 0.4(4)$ & & \\
\hline 2 & Arachis oil & ${ }^{a} 31 \cdot 0 \pm 1 \cdot 1(5)$ & ${ }^{b} 32.2 \pm 0.8(6)$ & $46 \cdot 0 \pm 1 \cdot 1(5)$ & $47.2 \pm 0.8(6)$ \\
\hline 2 & Melatonin in oil & $17.0 \pm 0.8(5)$ & $18.8 \pm 1.5(6)$ & $32.0 \pm 0.8$ & b $33.8 \pm 1.3(6)$ \\
\hline
\end{tabular}

Values are mean \pm s.e.m. for the no. of tammars in parentheses.

Within columns, means with same superscripts are not significantly different $(P>0.05$, Student's $t$ test $)$.

Melatonin concentrations in peripheral plasma. Under all three photoperiods melatonin was elevated during the dark phase (Text-fig. 3). An analysis of variance revealed that the melatonin profile of the first and second photoperiods (Text-fig. 3a, b) and of Day 0 and Day 5 (Text-fig. 3c) were significantly different from each other (VR 83.318, d.f. $3, P<0.001$ ). After the change from 10L:14D (Text-fig. 3a) to 15L:9D (Text-fig. 3b) the duration of the nocturnal elevation decreased and the levels at 04:00 and 06:00 h increased significantly $(P<0.05$; Least Significant Difference 

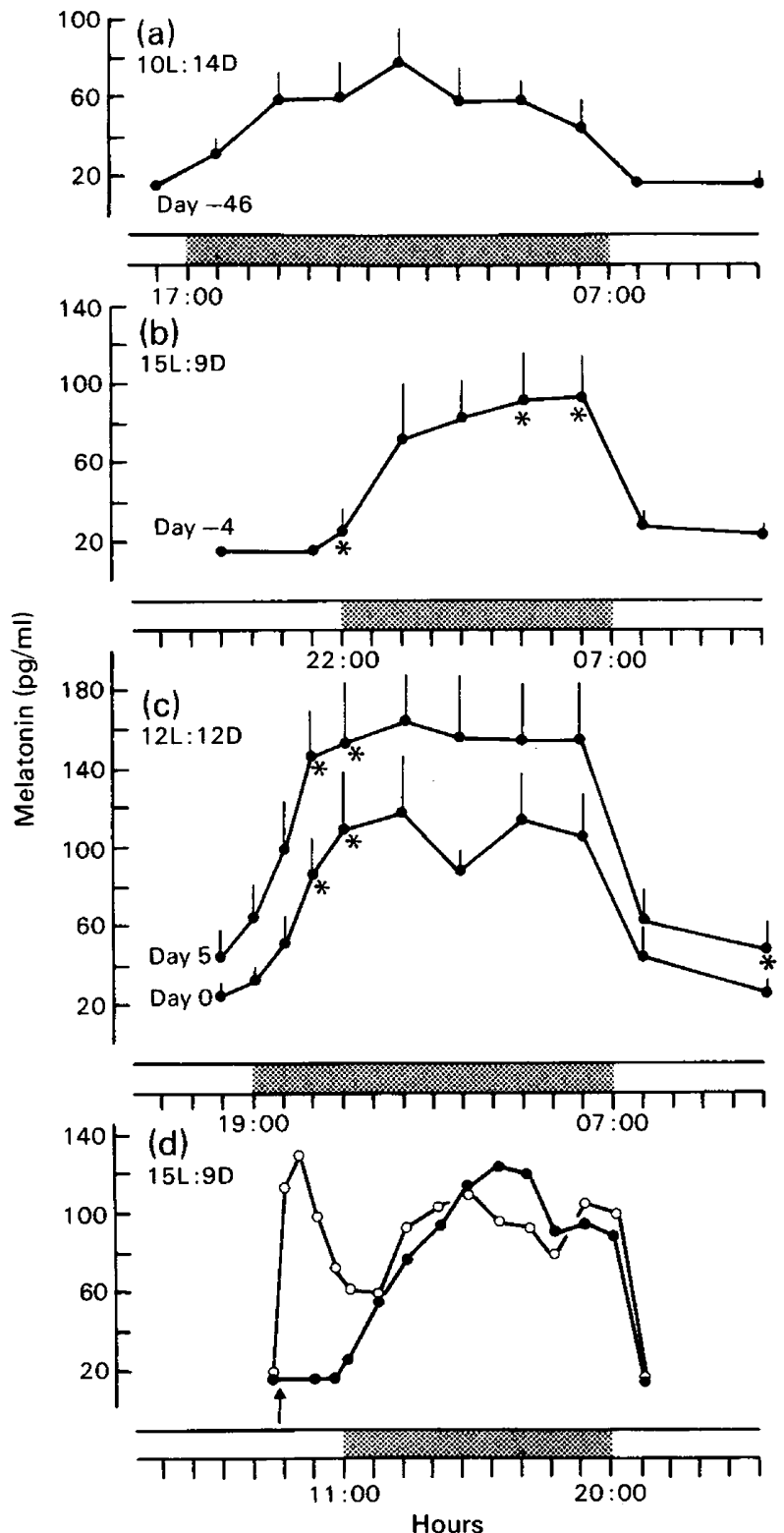

Text-fig. 3. Plasma melatonin concentrations (mean \pm s.e.m.) in tammars exposed to photoperiods of (a) 10L :14D, (b) 15L:9D, (c) 12L:12D and (d) two successive profiles from a tammar on $15 \mathrm{~L}: 9 \mathrm{D}$, the first without $(O)$ and the second $(O)$ after a s.c. injection of melatonin ( $\uparrow 2.25 \mathrm{~h}$ before dark. The stippled bars indicate the dark phase of each photoperiod. Asterisks denote a significant difference $(P<0.05)$ from the corresponding time of the previous photoperiod, i.e. values marked with asterisk in (b) are different from those in (a) and those in (c) are different from those in (b). Note that the duration of elevated melatonin is similar to that of the profile on Day 5 of $12 \mathrm{~L}: 12 \mathrm{D}$ (c).

method, Bliss, 1967). Conversely, after the change from 15L:9D (Text-fig. 3b) to 12L:12D (Textfig. $3 c$ ) the duration of the nocturnal elevation increased. This was seen on the first occasion (Day 0 ) on which the time of lights off was advanced by $3 \mathrm{~h}$, and by Day 5 there was a further increase. 
Since there was no change in the time of the decline of melatonin at lights on, the observed increase in duration by Day 5 was due to a progressive daily shift in the onset of the nocturnal rise (Text-fig. 4). Although it appears that the amplitude as well as the duration of the nocturnal elevation increased from 15L :9D to 12L :12D, the statistical analyses (L.S.D.; Bliss, 1967) showed that only the levels at $21: 00$ and $22: 00 \mathrm{~h}$ were significantly different $(P<0.05)$ (Text-fig. 3c).

The assay was able to measure exogenously administered melatonin, and the profiles for the female injected with melatonin are shown in Text-fig. 5. At the higher dose the peak concentrations

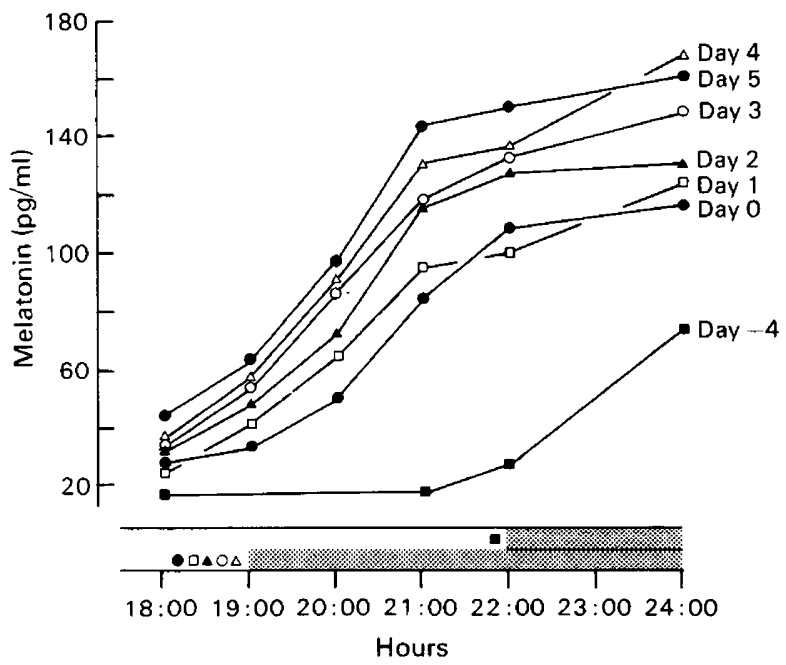

Text-fig. 4. Plasma melatonin concentrations (mean) of 4 tammars at the onset of the dark phase under 15L:9D (Day -4) and then 12L:12D (Days 0 to 5) to show the progressive daily shift in the onset of the nocturnal rise from Day 0 to Day 5. Mean values shown, error bars omitted for clarity. Stippled bars indicate the dark phase of each photoperiod.

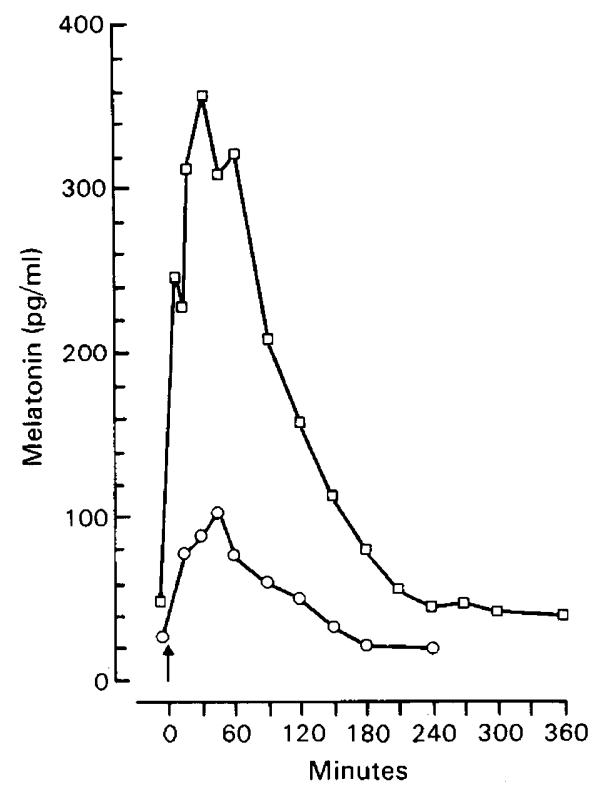

Text-fig. 5. Plasma melatonin concentrations in a tammar after a subcutaneous injection $(\uparrow)$ of melatonin, during the light phase of $15 \mathrm{~L}: 9 \mathrm{D}$, of $1 \mu \mathrm{g} / \mathrm{kg}(\square)$ or $400 \mathrm{ng} / \mathrm{kg}$ body weight $(O)$. 
exceeded the nocturnal levels observed in Exp. 1. However, the lower dose of $400 \mathrm{ng} / \mathrm{kg}$ resulted in peak concentrations similar to those of Day 5 in Exp. 1, and after $3 \mathrm{~h}$ these had returned to basal levels. In another trial this lower dose injected $2.5 \mathrm{~h}$ before lights off during 15L :9D effectively mimicked the duration of the nocturnal melatonin elevation seen on Day 5 of Exp. 1 (Text-fig. 3d).

\section{Experiment 2}

Of the 6 tammars in the control group 5 gave birth $46 \cdot 0 \pm 1 \cdot 1$ days after the start of injections, and all 6 came into oestrus 1 day later (Table 1; Text-fig. 1b). However, in the melatonin-treated group, 5 of the 6 tammars gave birth $32 \pm 0.8$ days after the start of treatment and all 6 came into oestrus on the subsequent day (Table 1; Text-fig. 1b). These intervals from the start of injections were significantly different between the two groups $(P<0.005$, Student's $t$ test). Nevertheless, the interval from transfer to outside pens on Day 15 to birth in the control group was not significantly different from the interval after the decrease in daylength in Exp. 1, and neither of these intervals was significantly different from the start of melatonin injection to birth or oestrus in Exp. 2 $(P>0.05$, Table 1).

\section{Discussion}

In this study we have shown that the radioimmunoassay developed by Kennaway et al. (1982) for the sheep will measure melatonin in the pineal and plasma of the tammar and have provided validation for its use in this species.

Plasma melatonin concentrations in the tammar were highest during the dark phase of the daily light/dark cycle, and the levels measured during both the light phase $(<16-62 \mathrm{pg} / \mathrm{ml}$, range of means) and the dark phase $(31-169 \mathrm{pg} / \mathrm{ml})$ are similar to those reported previously for the tammar (Renfree et al., 1981), and for the lizard, chicken, rat, pig, sheep, donkey, cow, camel and human (Kennaway, Frith, Phillipou, Matthews \& Seamark, 1977) and horse (Kilmer et al., 1982). The nocturnal elevation is of pineal origin in the tammar because it is abolished by superior cervical ganglionectomy (Renfree et al., 1981; McConnell, 1984) and pinealectomy (McConnell, 1984).

In Exp. 1 the duration of the nocturnal melatonin elevation corresponded to the duration of the dark phase of each photoperiod, and so decreased after the change from 10L:14D to $15 \mathrm{~L}: 9 \mathrm{D}$, and increased again after exposure to $12 \mathrm{~L}: 12 \mathrm{D}$. This suggested to us that these changes in the melatonin profile are important for the response of tammars to photoperiod, as has been shown for the ewe (Kennaway et al., 1982; Arendt, Symons, Laud \& Pryde, 1983; Bittman \& Karsch, 1984). The results of Exp. 2 supported this, since extending the duration of the nocturnal elevation by injection of melatonin fully mimicked the response observed after photoperiod change from 15L:9D to $12 \mathrm{~L}: 12 \mathrm{D}$.

Two models have been proposed to account for the role of melatonin in photoperiodic time measurement (see Lincoln, 1983), which are the duration of elevated melatonin and the time of day of exposure to elevated melatonin. However, neither model is fully satisfactory because none of the tammars showed blastocyst reactivation during the initial period of $10 \mathrm{~L}: 14 \mathrm{D}$ when they were also exposed to elevated melatonin at the critical time, but all responded to the similar profile of $12 \mathrm{~L}: 12 \mathrm{D}$ after they had experienced $15 \mathrm{~L}: 9 \mathrm{D}$. Although the present results cannot discriminate between the two models they suggest that it was the shift in the onset of the nocturnal rise of melatonin relative to the previously experienced profile that was the stimulatory signal for the animals.

The intervals from photoperiod change or melatonin treatment to birth or oestrus in the present experiments were the same as those reported by Sadleir \& Tyndale-Biscoe (1977) and Hinds \& den Ottolander (1983). In the three studies the interval is about 6 days longer than the interval of 26-28 days observed after removing the pouch young during decreasing daylength (Merchant, 1979), artificial short daylength of 9L:15D (Hinds \& den Ottolander, 1983) or treatment with 
bromocriptine (Tyndale-Biscoe \& Hinds, 1984). The onset of reactivation after hypophysectomy is equally rapid (Hinds, 1983) and it is suggested that in all these conditions a pituitary inhibition of the corpus luteum has been removed (Tyndale-Biscoe \& Hinds, 1981). Hinds \& den Ottolander (1983) showed that the longer interval after photoperiod change was associated with a delay of 6 days in the response of the corpus luteum and the results of Exp. 1 suggested that this interval was required for melatonin fully to assume the nocturnal profile appropriate to the longer dark phase of $12 \mathrm{~L}: 12 \mathrm{D}$. If this was so, treatment with exogenous melatonin that mimicked the $12 \mathrm{~L}: 12 \mathrm{D}$ profile should have resulted in birth/oestrus 26-28 days later. Experiment 2 was designed to test this hypothesis and, although the exogenous melatonin mimicked the Day 5 profile from the first day of treatment and blastocyst reactivation occurred in all the tammars, the interval was not reduced. This showed that melatonin is involved in the reproductive response of the tammar to photoperiod change and that the 6-day delay may be due to a delay in the response of the target tissue to melatonin. Since the response to hypophysectomy during increasing daylength is as rapid as during decreasing daylength, we conclude that the differences observed in the intervals to birth are not due to changes at the pituitary level and so may occur in the hypothalamic centre regulating pituitary secretion, and that this may be the target for melatonin. We therefore conclude that there is a basic pituitary inhibition of the corpus luteum, which when removed results in a 26-28-day interval to birth, and another ancillary photoperiod influence superimposed on it, from which the tammar takes an additional 6 days to recover. This latter influence involves the pineal gland through its circadian secretion of melatonin.

The rapid reproductive response of the tammar to melatonin and the identification of a precise period when it is effective makes the tammar a favourable species in which to examine further the role of the pineal in the central control of reproduction.

We thank Mr R. Geppert and Ms S. A. McConnell for assistance in handling and blood sampling the tammars, Ms S. Carpenter for the statistical analyses and Dr D. J. Kennaway for the gift of anti-melatonin antiserum. S.J.McC. was supported by a Commonwealth Postgraduate Research Award whilst at the Australian National University. We thank Professor R. F. Mark for the provision of facilities at A.N.U. and for co-supervision of S.J.McC.

\section{References}

Andrewartha, H.G. \& Barker, S. (1969) Introduction to a study of the ecology of the Kangaroo Island wallaby, Protemnodon eugenii (Desmarest) within Flinders Chase, Kangaroo Island, South Australia. Trans. Roy. Soc. S. Aust. 93, 127-132.

Arendt, J., Symons, A.M., Laud, C.A. \& Pryde, S.J. (1983) Melatonin can induce early onset of the breeding season in ewes. $J$. Endocr. 97, 395-400.

Bittman, E.L. \& Karsch, F.J. (1984) Nightly duration of pineal melatonin secretion determines the reproductive response to inhibitory daylength in the ewe. Biol. Reprod. 30, 585-593.

Bliss, C.I. (1967) Statistics in Biology, p. 252. McGrawHill, New York.

Carter, D.S. \& Goldman, B.D. (1983) Antigonadal effects of timed melatonin infusion in pinealectomized male Djungarian hamsters (Phodopus sungorus sungorus): duration is the critical parameter. Endocrinology 113, 1261-1267.

Hinds, L.A. (1983) Progesterone and prolactin in marsupial reproduction. Ph.D. thesis, Australian National University, Canberra.

Hinds, L.A. \& den Ottolander, R.C. (1983) Effect of changing photoperiod on peripheral plasma prolactin and progesterone concentrations in the tammar wallaby (Macropus eugenii). J. Reprod. Fert. 69, 631639.

Kennaway, D.J., Frith, R.G., Phillipou, G., Matthews, C.D. \& Seamark, R.F. (1977) A specific radioimmunoassay for melatonin in biological tissue and fluids and its validation by gas chromatographymass spectrometry. Endocrinology 101, 119-127.

Kennaway, D.J., Gilmore, T.A. \& Seamark, R.F. (1982) Effect of melatonin feeding on serum prolactin and gonadotropin levels and the onset of seasonal estrous cyclicity in sheep. Endocrinology 110, 1766-1772.

Kennaway, D.J., Sanford, L.M., Godfrey, B. \& Friesen, H.G. (1983) Patterns of progesterone, melatonin and prolactin secretion in ewes maintained in four different photoperiods. J. Endocr. 97, 229-242.

Kilmer, D.M., Sharp, D.C., Berglund, L.A., Grubaugh, W., McDowell, K.J. \& Peck, L.S. (1982) Melatonin rhythms in Pony mares and foals. J. Reprod. Fert., Suppl. 32, 303-307.

Lincoln, G. (1983) Melatonin as a seasonal time-cue: a commercial story. Nature, Lond. 302, 755.

Downloaded from Bioscientifica.com at 04/26/2023 01:52:25PM 
Lincoln, G.A., Almeida, O.F.X., Klandorf, H. \& Cunningham, R.A. (1982) Hourly fuctuations in the blood levels of melatonin, prolactin, luteinizing hormone, follicle-stimulating hormone, testosterone, tri-iodothyronine, thyroxine and cortisol in rams under artificial photoperiods, and the effects of cranial sympathectomy. J. Endocr. 92, 237-250.

McConnell, S.J. (1984) The pineal gland and reproduction in the tammar wallaby, Macropus eugenii. Ph.D. thesis, Australian National University, Canberra.

Merchant, J.C. (1979) The effect of pregnancy on the interval between one oestrus and the next in the tammar wallaby, Macropus eugenii. J. Reprod. Fert. 56, 459-463.

Reiter, R.J. (1974) Circannual reproductive rhythms in mammals related to photoperiod and pineal function: a review. Chronobiologia 1, 365-395.

Renfree, M.B. (1981) Marsupials: alternative mammals. Nature, Lond. 293, 100-101.

Renfree, M.B., Lincoln, D.W., Almeida, O.F.X. \& Short, R.V. (1981) Abolition of seasonal embryonic diapause in a wallaby by pineal denervation. Nature, Lond. 293, 138-139.
Sadleir, R.M.F.S. \& Tyndale-Biscoe, C.H. (1977) Photoperiod and the termination of embryonic diapause in the marsupial Macropus eugenii. Biol. Reprod. 16, 605-608.

Tyndale-Biscoe, C.H. (1980) Photoperiod and the control of seasonal reproduction in marsupials. In Endocrinology 1980, pp. 277-282. Eds I. A. Cumming, J. W. Funder \& F. A. O. Mendelsohn. Australian Academy of Science, Canberra.

Tyndale-Biscoe, C.H. \& Hinds, L.A. (1981) Hormonal control of the corpus luteum and embryonic diapause in macropodid marsupials. J. Reprod. Fert., Suppl. 29, 111-117.

Tyndale-Biscoe, C.H. \& Hinds, L.A. (1984) Seasonal patterns of circulating progesterone and prolactin and response to bromocriptine in the female tammar Macropus eugenii. Gen. comp. Endocr. 53, 58-68.

Received 31 July 1984 